
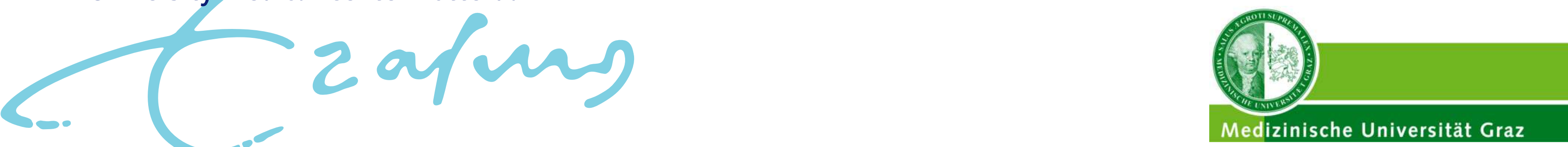

\title{
COMPARISON OF FREQUENCY DOMAIN AND CONTINOUS WAVE NEAR INFRARED SPECTROSCOPY DURING TRANSITION
}

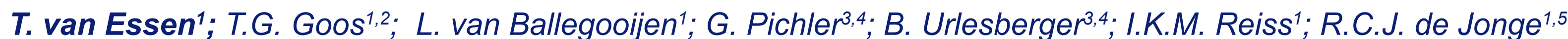
1. Department of Pediatrics, Division of Neonatology, Erasmus Medical Center - Sophia Children's Hospital, Rotterdam, The Netherlands. 2. Department of Biomechanical Engineering, Delft University of Technology, Delft, The Netherlands. 3. Research Unit for Neonatal Micro- and Macrocirculation, Department of Pediatrics and Adolescent Medicine, Medical University of Graz, Graz, Austria. 4. Division of Neonatology, Department of Pediatrics and Adolescent Medicine, Medical University of Graz, Graz, Austria. 5. Department of Neonatology,

BACKGROUND VU University Medical Center, Amsterdam, The Netherlands.

- Cerebral tissue oxygen saturation $\left(\mathrm{rCSO}_{2}\right)$ is non-invasively measured using near-infrared spectroscopy (NIRS)

- Proprietary algorithm hinder the comparison between different NIRS devices.

\section{AIMS}

To compare two techniques the frequency domain (FD) -NIRS (OxiplexTS) and continuous wave (CW) -NIRS (Invos) in measuring the $\mathrm{rcSO}_{2}$ during transition in preterm neonates.

\section{METHODS}

In this prospective observational study, newborn infants, born $\geq 30$ weeks and $<37$ weeks GA, were measured during 15 minutes after birth with the FD-NIRS. For comparison, CW-NIRS measurements were provided by Graz University Medical Center. Post-processing the measurements were analysed using mixed models.

\section{RESULTS}

- After checking for potential confounders, non-linear time, technique, respiratory support and their interaction with time were included in de model.

- FD-NIRS measured $\mathrm{rCSO}_{2}$-values are consistently higher in the first 12 minutes after birth.

- The overall effect of technique ( $\mathbf{p}=\mathbf{0 . 0 1 1}$ ) remained statistically significant after adjustment for respiratory support ( $p=\mathbf{0 . 0 0 1})$

\section{CONCLUSION}

- Different measurement techniques have an influence on the measured $\mathrm{rcSO}_{2}$

- These differences seemd most pronounced during the first minutes of immediate transition.

CW-NIRS (Invos) FD-NIRS (OxiplexTS)

$\mathrm{n}$ 58

Female gender

$30(52 \%)$

$14(37 \%)$

Gestational age (wk) $34 \%[324 / 7-35 \% / 7] \quad 32 \frac{2 / 7}{3}\left[314 / 7-34 \frac{1 / 7}{7}\right]$

Birthweight (g) 2066 [1172 - 2366] 1763 [1480 - 2011]

Head circumference $(\mathrm{cm})$

$32.0[31.0-33.0]$

$29.5[28.0-31.8]$

Arterial umbilical cord $\mathrm{pH}$

$7.31[7.28-7.34]$

$7.29[7.26-7.34]$

Apgar at minute 5

$$
9 \text { [8 - 10] }
$$

Caesarean section

$58(100 \%)$

$27(71 \%)$

Respiratory support

$$
34(59 \%)
$$

\section{Reanimation ${ }^{1}$}

$2(3 \%)$

$0(0 \%)$

$\mathrm{SGA}^{2}$

$7(12 \%)$

$7(18 \%)$

Table 1 : Demographic and clinical data. Values are median [IQR] or $n(\%) ;{ }^{1}$ unknown in $n=1$ from CW-NIRS group; ${ }^{2}$ unknown in $n=1$ from CW-NIRS group.
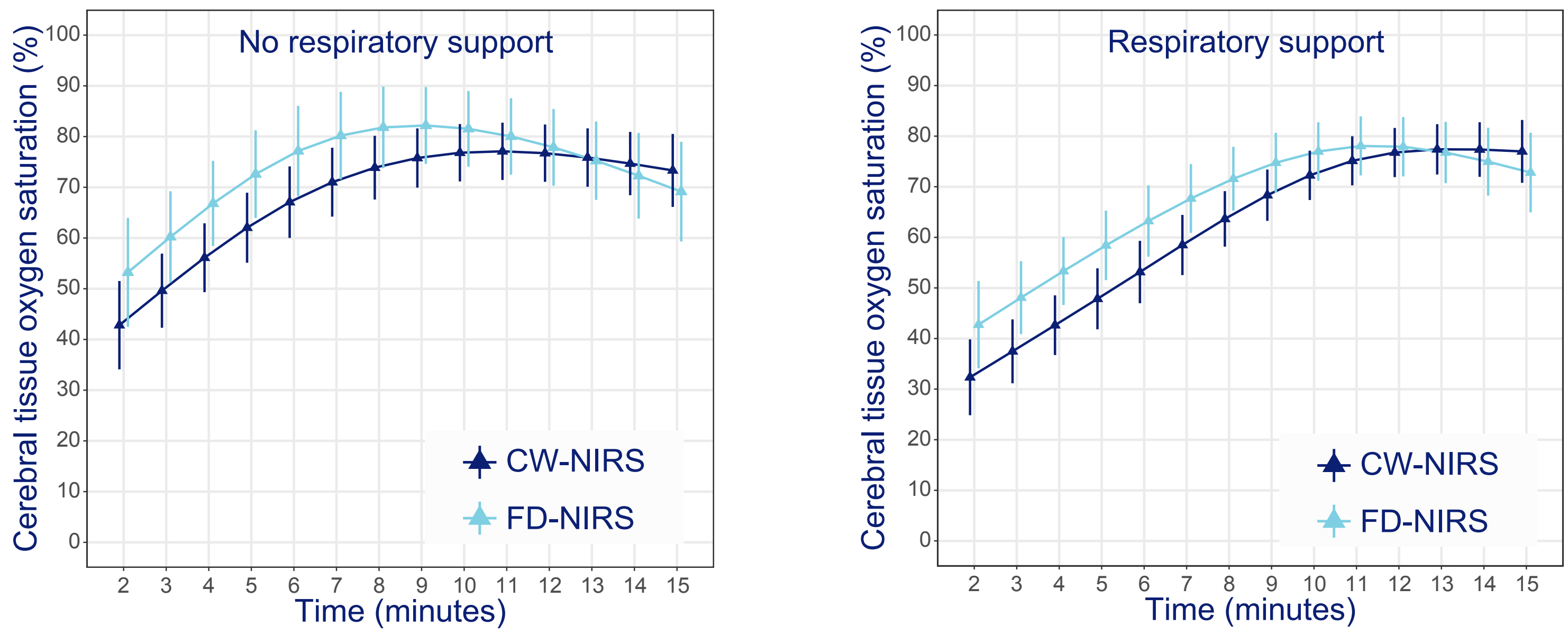

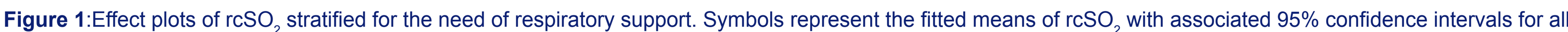
different time points, based on a mixed model including non-linear time, technique, respiratory support and their interaction with time. 